\title{
Prediction of hypertension by different anthropometric indices in adults: the change in estimate approach
}

\author{
Nguyen T Tuan ${ }^{1,2}$, Linda S Adair ${ }^{1,2}$, June Stevens ${ }^{1,3}$ and Barry M Popkin 1,2,* \\ 'Department of Nutrition, University of North Carolina, Chapel Hill, NC, USA: ${ }^{2}$ Carolina Population Center, \\ University of North Carolina, 123 West Franklin Street, Chapel Hill, NC 27516-3997, USA: ${ }^{3}$ Department of \\ Epidemiology, University of North Carolina, Chapel Hill, NC, USA
}

Submitted 10 September 2008: Accepted 20 July 2009: First published online 17 September 2009

\begin{abstract}
Objective: To examine the relative contribution for the prediction of hypertension by waist circumference (WC), waist:stature ratio (WSR) or waist:hip ratio (WHR) with that by BMI, to ascertain if WC, WSR or WHR enhances the prediction of hypertension by BMI.

Design: Population-based, cross-sectional study. A change of $\geq 10 \%$ in the prevalence ratio of $\mathrm{BMI}(\mathrm{PR})$ or the area under the receiver-operating characteristic curve (AUC) when WC, WSR or WHR was added to a model with BMI was used as the criterion for significant contribution to the prediction of hypertension by BMI. For greater contributions $(\geq 10 \%)$ these waist measures were considered as better predictors.

Setting: Nine provinces in China.

Subjects: Chinese adults aged 18 to 65 years ( $n 7336$ ) who participated in the 2004 China Health and Nutrition Survey.

Results: The prevalence of hypertension (17\% and $23 \%$ for women and men, respectively) was significantly related to increased BMI, WC, WSR and WHR ( $P$ for trend $<0 \cdot 001)$. Although there was a better model fit when WC, WSR or WHR was added to a model with BMI $(P<0 \cdot 05$; likelihood ratio test $)$, the changes in PR and AUC were $<10 \%$ and $<5 \%$, respectively. The sex-specific AUC for the prediction of hypertension by BMI (of $0 \cdot 7-0 \cdot 8$ ) was similar to that by WC, WSR or WHR. Conclusions: The waist indices do not perform better than BMI or markedly enhance the prediction of increased hypertension risk by BMI in Chinese adults.

Keywords
Anthropometry
Hypertension
Chinese adults
Population study
Receiver-operating characteristic curve
\end{abstract}

Anthropometric indicators for body fat are widely used to predict increased chronic disease risk at the individual and population level. Compared with BMI, which is a good indicator for body fatness in adults at the population level, waist circumference (WC), waist:stature ratio (WSR) and waist:hip ratio (WHR) provide additional information about central fat distribution ${ }^{(1,2)}$. Studies aimed at determining whether WC, WHR and WSR predict hypertension better than BMI or add to the prediction of hypertension have shown controversial results in both Western ${ }^{(3-5)}$ and Asian populations ${ }^{(6-12)}$. As a criterion for judging predictions of alternative indicators these studies used a larger point estimate, a $P$ value $<0.05$ or a non-overlap of $95 \%$ confidence intervals. Because $P$ values and $95 \%$ confidence intervals are driven by both the magnitude of effect and the sample size ${ }^{(13,14)}$, different conclusions would result from different sample sizes or BMI distributions.

The present study undertook a comparison of the predictive ability of these alternative indicators as they relate to Chinese adults. We utilized two criteria that are less affected by sample size, the difference in prevalence ratio and the area under the receiver-operating characteristic curve ${ }^{(15,16)}$, to: (i) compare the prediction of hypertension by WC, WSR or WHR with that by BMI; and (ii) determine if WC, WSR or WHR enhances the prediction of hypertension by BMI in 18- to 65-year-old Chinese adults.

\section{Methods}

\section{Study sample}

We used data from the China Health and Nutrition Survey (CHNS) conducted in 2004 with a representative sample drawn from nine provinces in China (Guangxi, Guizhou, Heilongiiang, Henan, Hubei, Hunan, Jiangsu, Liaoning and Shandong). This sample was diverse, with variation found in a wide-ranging set of socio-economic factors (income, employment, education and modernization) and other related health, nutritional and demographic measures ${ }^{(17,18)}$. Of the 8258 participants aged 18 to 65 years who were men, non-pregnant or non-lactating women, $7336(89 \%)$ had complete and plausible measurements of 
weight, height, WC, hip circumference (HC) and blood pressure (e.g. BMI of $15-35 \mathrm{~kg} / \mathrm{m}^{2}$, weight of $30-150 \mathrm{~kg}$, height of $130-190 \mathrm{~cm}$, WC of $45-150 \mathrm{~cm}, \mathrm{HC}$ of 55-155 cm, WHR of $0 \cdot 6-1 \cdot 1$, difference between systolic and diastolic blood pressure $\geq 10 \mathrm{mmHg}$ ). We only included 18- to 65-year-old adults, non-pregnant and non-lactating women because adolescents, the elderly, and pregnant or lactating women require different BMI and WC cut-offs ${ }^{(19)}$. The exclusion of participants with extreme values in anthropometric measurements and blood pressure helped to increase the estimate precision without changing the overall results.

\section{Measurements}

Three blood pressure measurements were taken in a seated position and on the right arm by trained health workers who followed a standardized procedure using regularly calibrated mercury sphygmomanometers with appropriate-sized cuffs. Systolic blood pressure was measured at the first appearance of a pulse sound (Korotkoff phase 1) and diastolic blood pressure at the disappearance of the pulse sound (Korotkoff phase 5). Three measurements of systolic or diastolic blood pressure were averaged to reduce the effect of measurement error. Hypertension was defined as systolic blood pressure $\geq 140 \mathrm{~mm} \mathrm{Hg}$, diastolic blood pressure $\geq 90 \mathrm{~mm} \mathrm{Hg}$ or being previously diagnosed by a doctor ${ }^{(20)}$. The definition of hypertension was not based on the use of an antihypertensive medication because, in the present sample, a small proportion of Chinese adults were diagnosed $(<7 \%)$ or treated $(<5 \%)$ with an antihypertensive medication and none used an antihypertensive medication without being diagnosed by a doctor. Moreover, sensitivity analysis showed that incorporating these measures produced similar findings.

BMI was calculated based on weight and height measured by trained health workers who followed standardized procedures using regularly calibrated equipment (SECA 880 scales and SECA 206 wall-mounted metal tapes). The health workers used a non-elastic tape to measure WC at a point midway between the lowest rib and the iliac crest in a horizontal plane and $\mathrm{HC}$ at the point yielding the maximum circumference over the buttocks ${ }^{(17,18)}$. WSR (WC/height) and WHR (WC/HC) were calculated based on the measured WC, height and HC. Covariates such as age, sex, smoking habits, alcohol consumption and place of residence were collected by direct interviews.

\section{Statistical analysis}

We used Poisson regression models to examine the association between BMI and hypertension. Potential confounding factors, such as age (centred at the mean age of 45 years), sex, smoking habits (dichotomized to never smoker or ever smoker), alcohol consumption (dichotomized to current drinker or non-drinker) and place of residence (urban or rural), were also taken into account in regression models. A covariate was considered as an effect measure modifier if its interaction term with BMI in regression models had a $P$ value of $<0 \cdot 15$ ( $\chi^{2}$ test $)$ or as a confounder if it caused a change in prevalence ratios of BMI (PR) of $\geq 10 \%{ }^{(15)}$. Based on these criteria, age was the only effect measure modifier and there were no confounders. To make our results comparable with those of other studies, we stratified our analyses by sex in crude, age-adjusted and age-specific models. BMI, WC, WSR and WHR were kept in continuous scale to maximize the power of statistical tests.

The receiver-operating characteristic (ROC) curve is an analytical approach to define the highest combination of sensitivity and specificity of a screening test. The approach has been widely used to determine a cut-off point for decision making (e.g. having a disease or not) in both public health and clinical settings ${ }^{(7,10,16)}$. The most common measurement to quantify the performance of a screening test is the area under the ROC curve (AUC), which shows the ability of a test to correctly classify those with and without the disease. For example, an AUC value of 0.75 indicates that, $75 \%$ of the time, a randomly selected individual from the diseased group has a test value larger than that for a randomly selected individual from the nondiseased group. AUC values range from $0 \cdot 5$ (no prediction) to $1 \cdot 0$ (perfect prediction). The AUC values are usually used as criteria to compare overall performances of different screening tests ${ }^{(16)}$. In the current study, AUC values were estimated by using logistic regression models.

To determine if the inclusion of WC, WSR or WHR improved the prediction of hypertension by BMI, we estimated the change in sex-specific PR (from Poisson regression models) and sex-specific AUC (from logistic regression models) between a model with $\mathrm{BMI}+\mathrm{WC}$, BMI + WSR or BMI + WHR and a model with BMI alone. A change in PR or AUC of $\geq 10 \%$ was used as a criterion for a significant contribution of WC, WSR or WHR to the prediction of hypertension by BMI. We separately compared sex-specific AUC between a model with WC, WSR or WHR and a model with BMI to examine if any was better than $\mathrm{BMI}$ in predicting hypertension; an increase of $\geq 10 \%$ in AUC was used as a criterion for a superior prediction. We used the criterion of $\geq 10 \%$ because it is arbitrarily used to determine a notable confounding factor ${ }^{(15)}$.

To facilitate the comparison with previous studies that use $P$ value as a decision criterion, we compared the fit of a model with BMI with that of a model with $\mathrm{BMI}+\mathrm{WC}$, $\mathrm{BMI}+\mathrm{WSR}$ or BMI + WHR. A $P$ value of $<0 \cdot 05$ (likelihood ratio test) was used as the criterion for a significant increase in model fit. In addition, independent $t$ tests $(P$ value $<0.05)$ were used to compare PR of BMI from different regression models (e.g. models hypertension $=$ $\mathrm{BMI}+\mathrm{WC} v$. hypertension $=\mathrm{BMI})$. We did not adjust for the cluster effects from the CHNS because the adjustment did not affect point estimates of PR or AUC, which were used to estimate percentage change in PR or AUC. To 
evaluate if these findings were consistent at different BMI levels, we performed similar analyses for participants with $\mathrm{BMI}<23 \mathrm{~kg} / \mathrm{m}^{2}$ and $\mathrm{BMI} \geq 23 \mathrm{~kg} / \mathrm{m}^{2}$ (data are presented in Supplementary tables 1 and 2). All analyses were performed using the STATA statistical software package version 9·2 (Stata Inc., College Station, TX, USA).

\section{Role of the funding sources and etbical considerations}

The authors had full access to all of the data in the study and take responsibility for the integrity of the data and the accuracy of the data analysis. The sponsors were not involved in the study design, the collection, analysis or interpretation of the data, the writing of the manuscript, or the decision to submit the manuscript for publication. Written informed consent was obtained from each participant for each CHNS round. We certify that all applicable institutional and governmental regulations concerning the ethical use of human volunteers were followed during this research. The relevant Institutional Review Boards have reviewed and approved the study.

\section{Results}

The crude prevalence of hypertension among men of $23 \cdot 0 \%$ (95\% CI 21.6, 24.4\%) was higher than that among women $(16 \cdot 8 \%$; $95 \%$ CI $15 \cdot 6,18 \cdot 0 \% ; P<0 \cdot 001)$. The mean systolic and diastolic blood pressures were higher among men (122 and $80 \mathrm{mmHg}$, respectively) compared with women (118 and $77 \mathrm{mmHg} ; P<0 \cdot 001$ ). Only a small proportion of the Chinese adults was diagnosed or treated with any antihypertensive medications (about 5\%). A small proportion of hypertensive participants, identified by measured blood pressures, was diagnosed by a doctor (35\%) or treated with an antihypertensive medication (25\%). Men and women had similar mean $\left(23 \mathrm{~kg} / \mathrm{m}^{2}\right)$ and distribution of BMI. Men had higher means of WC, HC and WHR, but smaller mean WSR compared with women. The proportions of Chinese men who were smokers $(58 \cdot 8 \%)$ and alcohol drinkers $(62 \cdot 3 \%)$ were much higher than those of women (Table 1 ).

There was a significant trend of increased prevalence of hypertension with an increase in BMI, WC, WSR or WHR ( $P$ for trend $<0 \cdot 001$ ) in both men and women (Fig. 1).

On average, each unit increase in BMI was associated with an $18 \%$ and $14 \%$ increase in PR for hypertension in women and men, respectively $(P<0 \cdot 001$; crude models). There was about a $15 \%$ increase in PR associated with each unit increase in BMI in age-adjusted and age-specific models $(P<0 \cdot 001)$. Although there was an increase in model fit when adding WC, WSR or WHR to a model with BMI $(P<0.05$ in almost all of the models; likelihood ratio test), the changes in $\mathrm{PR}$ were $<10 \%$ in the crude models and $<5 \%$ in the age-adjusted and age-specific models (Table 2). The changes in PR increased slightly

Table 1 Characteristicst of the 18- to 65 -year-old Chinese participantsł

\begin{tabular}{|c|c|c|c|c|}
\hline & \multicolumn{2}{|c|}{ Women (n 3794) } & \multicolumn{2}{|c|}{ Men (n 3542) } \\
\hline & Mean or \% & $95 \% \mathrm{Cl}$ & Mean or \% & $95 \% \mathrm{Cl}$ \\
\hline Age (years) & $44 \cdot 0$ & $43 \cdot 6,44 \cdot 4$ & $43 \cdot 7$ & $43 \cdot 4,44 \cdot 1$ \\
\hline \multicolumn{5}{|l|}{ Blood pressure status } \\
\hline Hypertension§ (\%) & $16 \cdot 8$ & $15 \cdot 6,18 \cdot 0$ & $23 \cdot 0^{*}$ & $21 \cdot 6,24 \cdot 4$ \\
\hline Hypertension diagnosedll (\%) & $6 \cdot 6$ & $5 \cdot 8,7 \cdot 4$ & $6 \cdot 3$ & $5 \cdot 5,7 \cdot 1$ \\
\hline Use antihypertensive medication (\%) & $5 \cdot 0$ & $4 \cdot 3,5 \cdot 7$ & $4 \cdot 1$ & $3 \cdot 4,4 \cdot 7$ \\
\hline Systolic blood pressure $(\mathrm{mmHg})$ & $117 \cdot 8$ & $117 \cdot 3,118 \cdot 4$ & $122 \cdot 1^{*}$ & $121 \cdot 6,122 \cdot 6$ \\
\hline Diastolic blood pressure $(\mathrm{mmHg})$ & $76 \cdot 8$ & $76 \cdot 4,77 \cdot 1$ & $80 \cdot 1^{*}$ & $79 \cdot 8,80 \cdot 4$ \\
\hline BMI $\left(\mathrm{kg} / \mathrm{m}^{2}\right)$ & $23 \cdot 1$ & $23 \cdot 0,23 \cdot 2$ & $23 \cdot 1$ & $23 \cdot 0,23 \cdot 2$ \\
\hline$<18.5 \mathrm{~kg} / \mathrm{m}^{2}(\%)$ & $6 \cdot 0$ & $5 \cdot 2,6 \cdot 7$ & $4 \cdot 9$ & $4 \cdot 2,5 \cdot 7$ \\
\hline $18 \cdot 5-22 \cdot 9 \mathrm{~kg} / \mathrm{m}^{2}(\%)$ & $47 \cdot 3$ & $45 \cdot 7,48 \cdot 8$ & $48 \cdot 0$ & $46 \cdot 3,49 \cdot 6$ \\
\hline $23.0-24.9 \mathrm{~kg} / \mathrm{m}^{2}(\%)$ & $19 \cdot 7$ & $18 \cdot 4,21 \cdot 0$ & $21 \cdot 6$ & $20 \cdot 2,23 \cdot 0$ \\
\hline$\geq 25.0 \mathrm{~kg} / \mathrm{m}^{2}(\%)$ & $27 \cdot 1$ & $25 \cdot 7,28 \cdot 5$ & $25 \cdot 5$ & $24 \cdot 1,26 \cdot 9$ \\
\hline WC $(\mathrm{cm})$ & $78 \cdot 7$ & $78 \cdot 4,79 \cdot 0$ & $82 \cdot 5^{\star}$ & $82 \cdot 2,82 \cdot 9$ \\
\hline $\mathrm{HC}(\mathrm{cm})$ & $93 \cdot 2$ & $92 \cdot 9,93 \cdot 5$ & $94 \cdot 0^{*}$ & $93 \cdot 7,94 \cdot 3$ \\
\hline WHR & 0.84 & $0.84,0.85$ & $0 \cdot 88^{*}$ & $0.88,0.88$ \\
\hline WSR & 0.50 & $0.50,0.51$ & $0 \cdot 49^{*}$ & $0.49,0.50$ \\
\hline \multicolumn{5}{|l|}{ Smoking status } \\
\hline Former smoker (\%) & $0 \cdot 1$ & $0 \cdot 0,0.2$ & $5 \cdot 6^{*}$ & $4 \cdot 8,6 \cdot 3$ \\
\hline Current smoker (\%) & $3 \cdot 1$ & $2 \cdot 6,3 \cdot 7$ & $58 \cdot 8^{*}$ & $57 \cdot 1,60 \cdot 4$ \\
\hline Alcohol drinker (\%) & $9 \cdot 0$ & $8 \cdot 0,9 \cdot 9$ & $62 \cdot 3^{*}$ & $60 \cdot 7,63 \cdot 9$ \\
\hline Urban residence (\%) & $34 \cdot 0$ & $32 \cdot 5,35 \cdot 5$ & $33 \cdot 9$ & $32 \cdot 3,35 \cdot 4$ \\
\hline
\end{tabular}

WC, waist circumference; HC, hip circumference; WHR, waist:hip ratio; WSR, waist:stature ratio.

Significantly different compared with women (independent $t$ test for continuous variables or $\chi^{2}$ test for categorical variables): ${ }^{\star} P<0 \cdot 001$.

+Values are means or percentages with $95 \%$ confidence intervals.

$\ddagger$ The samples included participants who were 18- to 65-year-old men and women (not pregnant or lactating), for whom measurements of anthropometric indices and blood pressure were complete and plausible (e.g. BMl of $15-35 \mathrm{~kg} / \mathrm{m}^{2}$, weight of $30-150 \mathrm{~kg}$, height of $130-190 \mathrm{~cm}$, WC of $45-150 \mathrm{~cm}$, HC of $55-155 \mathrm{~cm}$, WHR of $0 \cdot 6-1 \cdot 1$, difference between systolic and diastolic blood pressure $\geq 10 \mathrm{mmHg}$ ).

$\S$ Hypertension was defined as systolic blood pressure $\geq 140 \mathrm{mmHg}$, diastolic blood pressure $\geq 90 \mathrm{mmHg}$ or being diagnosed by a doctor.

IIHypertension diagnosed: proportion of the population that was diagnosed as being hypertensive by a doctor.

- Use anti-hypertensive medication: proportion of the population that used any antihypertensive medications. 

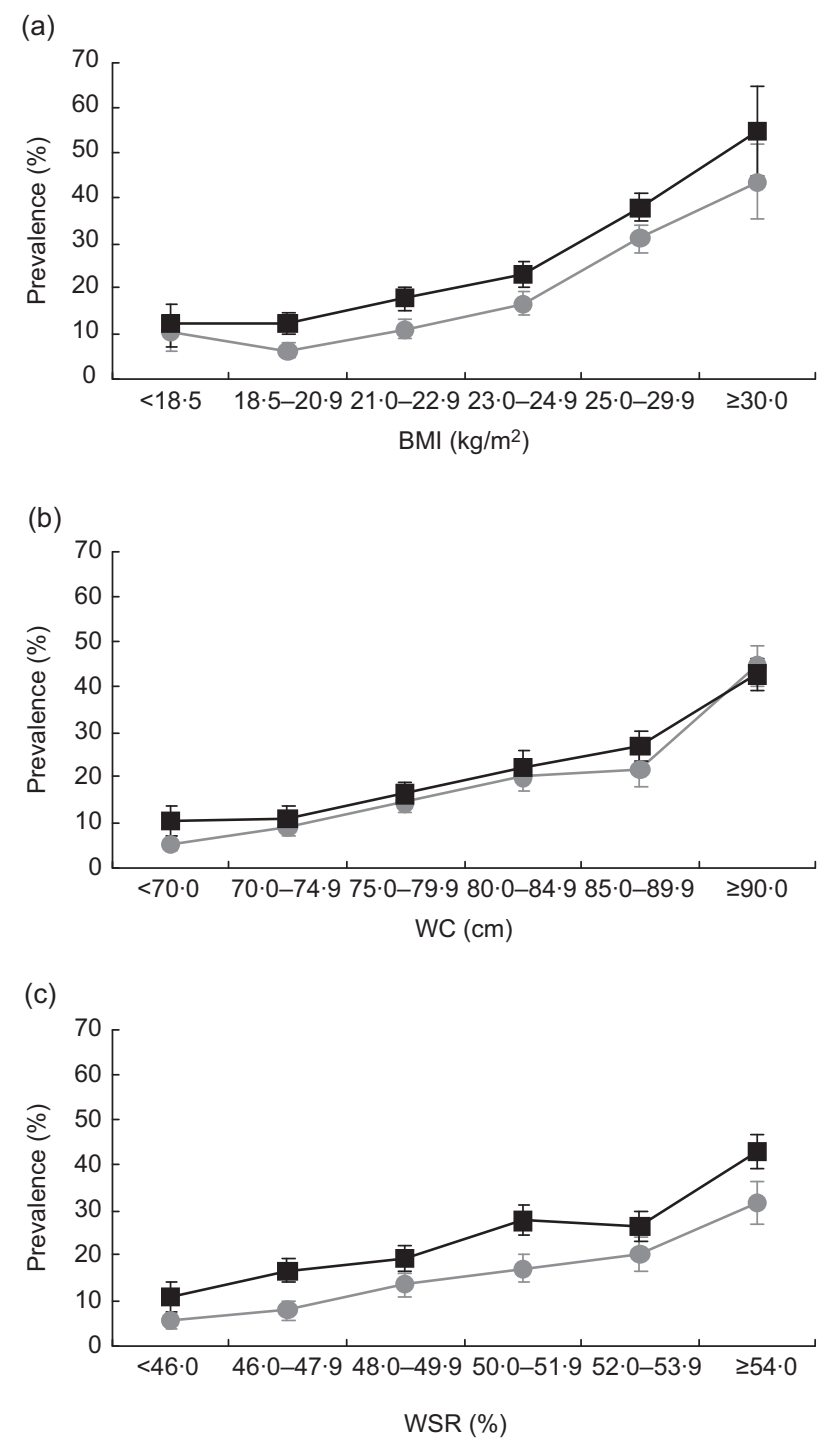

Fig. 1 Prevalence and $95 \% \mathrm{Cl}$ of hypertension by levels of (a) $\mathrm{BMI}$, (b) waist circumference (WC) and (c) waist:stature ratio (WSR). Hypertension was defined as systolic blood pressure $\geq 140 \mathrm{mmHg}$, diastolic blood pressure $\geq 90 \mathrm{mmHg}$ or being diagnosed by a doctor. The samples included participants who were 18- to 65-year-old men ( $\square, n$ 3542) and women (o, not pregnant or lactating; $n$ 3794), for whom measurements of anthropometric indices and blood pressure were complete and plausible (e.g. BMI of $15-35 \mathrm{~kg} / \mathrm{m}^{2}$, weight of $30-150 \mathrm{~kg}$, height of $130-190 \mathrm{~cm}$, WC of $45-150 \mathrm{~cm}$, hip circumference of $55-155 \mathrm{~cm}$, waist:hip ratio of $0 \cdot 6-1 \cdot 1$, difference between systolic and diastolic blood pressure $\geq 10 \mathrm{mmHg}$ ). $P$ for trend $<0.001$ for all

( $<10 \%$ except for WSR in the crude model for women) among participants with $\mathrm{BMI}<23 \mathrm{~kg} / \mathrm{m}^{2}$ (Supplementary table 1).

The AUC estimates for the prediction of hypertension by BMI (about $0 \cdot 7-0 \cdot 8$ ) were higher among women $(P<0.05$ in age-adjusted and age-specific estimates). Although there was an increase in model fit when adding WC, WSR or WHR to a model with BMI $(P<0.05$ in almost all of the models; likelihood ratio test), the changes in AUC were $<5 \%$ in the crude models and $<1 \%$ in the age-adjusted and age-specific models (Table 3). The changes in AUC increased slightly $(<10 \%$ except for WSR in crude model for women) among participants with $\mathrm{BMI}<$ $23 \mathrm{~kg} / \mathrm{m}^{2}$ (Supplementary table 2 ).

Models with WC or WSR provided similar AUC compared with models with BMI for men, women and both sexes (difference in AUC $<2.5 \% ; P>0 \cdot 05$ ). A model with WHR had about 4-10\% lower AUC compared with a corresponding model with BMI (Table 3). There were some increases $(<10 \%$ except for WSR in crude model for women) in the prediction of hypertension by WC, WSR and WHR compared with that by BMI among participants with BMI $<23 \mathrm{~kg} / \mathrm{m}^{2}$ (Supplementary table 2 ).

\section{Discussion}

To our knowledge, we are the first to use changes in PR and AUC as the criteria to evaluate whether WC, WSR or WHR adds to the prediction of hypertension by BMI in an Asian population. Our findings show that even though WC, WSR and WHR are predictors of hypertension and improve the fit of models with BMI, they do not perform better than BMI or add meaningfully to the prediction of hypertension outcome by BMI in Chinese adults.

We observed a significant trend of increased prevalence of hypertension with increased BMI, WC, WSR and WHR. This finding was similar to results from studies in $\operatorname{Asian}^{(6,7,9,10,21-25)}$ and Western populations ${ }^{(5,26,27)}$. Increased blood pressure is associated with increased BMI because an increase in body weight and thus BMI is related to an increase in body fluid volume, peripheral resistance (e.g. hyperinsulinaemia, cell membrane alteration and hyperactivity of the rennin-angiotensin system lead to functional constriction and structural hypertrophy) and cardiac output ${ }^{(28)}$. The positive correlation between WC, WSR or WHR and prevalence of hypertension could be explained by an increase in visceral fat that leads to increased leptin and insulin resistance and worse lipid profiles ${ }^{(28,29)}$.

There are several possible explanations for the finding that WC and WSR did not perform better or add to the prediction of hypertension by BMI in this population. First, WC and WSR were highly correlated with BMI (sex-specific Pearson correlation coefficients were about $0 \cdot 75$ ). The high correlation leads to a large overlap among the predictions explained by WC, WSR and BMI. Second, compared with other races and ethnicities, Asians accumulate more total body fat and visceral fat with an increase in body weight $^{(30-32)}$. In addition, WC and WSR are only proxy indicators for total body fat and visceral fat ${ }^{(1)}$ while increased visceral fat is a predictor for an increase in metabolic risk ${ }^{(2)}$.

The findings that WC, WSR and WHR were not superior to BMI in the prediction of hypertension are consistent with those from a representative sample of 55563 Taiwanese 
Table 2 Sex-specific prevalence ratios of BMI for hypertensiont, $\ddagger$

\begin{tabular}{|c|c|c|c|c|c|c|c|c|c|}
\hline \multirow[b]{2}{*}{ Model } & \multirow[b]{2}{*}{ Independent variable } & \multicolumn{4}{|c|}{ Women (n 3794) } & \multicolumn{4}{|c|}{ Men ( $n$ 3542) } \\
\hline & & PR & $95 \% \mathrm{Cl}$ & $\%$ change & $P$ valuell & PR & $95 \% \mathrm{Cl}$ & $\%$ change & $P$ value \\
\hline \multirow[t]{4}{*}{ Crude model } & BMI & $1 \cdot 18$ & $1 \cdot 16,1 \cdot 20$ & & & $1 \cdot 14$ & $1 \cdot 12,1 \cdot 17$ & & \\
\hline & $B M I+W C$ & $1 \cdot 08^{*}$ & $1 \cdot 05,1 \cdot 11$ & $8 \cdot 8$ & $<0.001$ & $1 \cdot 08^{*}$ & $1 \cdot 05,1 \cdot 11$ & $5 \cdot 7$ & $<0.001$ \\
\hline & BMI + WSR & $1 \cdot 07^{*}$ & $1 \cdot 04,1 \cdot 11$ & $9 \cdot 5$ & $<0.001$ & $1 \cdot 06^{\star}$ & $1 \cdot 03,1 \cdot 10$ & $7 \cdot 1$ & $<0.001$ \\
\hline & $\mathrm{BMI}+\mathrm{WHR}$ & $1 \cdot 15$ & $1 \cdot 13,1 \cdot 18$ & $2 \cdot 1$ & $<0.001$ & $1 \cdot 11$ & $1 \cdot 09,1 \cdot 14$ & $2 \cdot 8$ & $<0.001$ \\
\hline \multirow[t]{4}{*}{ Age-adjustedtt } & BMI & $1 \cdot 14$ & $1 \cdot 11,1 \cdot 16$ & & & $1 \cdot 14$ & $1 \cdot 12,1 \cdot 16$ & & \\
\hline & BMI + WC & $1 \cdot 10$ & $1 \cdot 06,1 \cdot 13$ & $3 \cdot 6$ & 0.003 & 1.09 & $1 \cdot 05,1 \cdot 12$ & $4 \cdot 7$ & $<0.001$ \\
\hline & BMI + WSR & $1 \cdot 11$ & $1 \cdot 07,1 \cdot 14$ & $2 \cdot 6$ & 0.029 & 1.09 & $1 \cdot 06,1 \cdot 13$ & $4 \cdot 1$ & $<0.001$ \\
\hline & $\mathrm{BMI}+\mathrm{WHR}$ & $1 \cdot 13$ & $1 \cdot 11,1 \cdot 16$ & $0 \cdot 6$ & $0 \cdot 136$ & $1 \cdot 12$ & $1 \cdot 09,1 \cdot 14$ & $2 \cdot 0$ & $<0.001$ \\
\hline \multirow[t]{4}{*}{ Age-specificł‡ } & BMI & $1 \cdot 16$ & $1 \cdot 13,1 \cdot 20$ & & & $1 \cdot 15$ & $1 \cdot 12,1 \cdot 17$ & & \\
\hline & BMI + WC & $1 \cdot 12$ & $1 \cdot 08,1 \cdot 16$ & $3 \cdot 7$ & 0.002 & 1.09 & $1 \cdot 06,1 \cdot 13$ & $4 \cdot 7$ & $<0.001$ \\
\hline & BMI + WSR & $1 \cdot 13$ & $1 \cdot 09,1 \cdot 17$ & $2 \cdot 7$ & 0.022 & $1 \cdot 10$ & $1 \cdot 07,1 \cdot 14$ & $4 \cdot 1$ & $<0.001$ \\
\hline & $\mathrm{BMI}+\mathrm{WHR}$ & $1 \cdot 16$ & $1 \cdot 13,1 \cdot 19$ & 0.6 & $0 \cdot 130$ & $1 \cdot 12$ & $1 \cdot 10,1 \cdot 15$ & $2 \cdot 0$ & $<0.001$ \\
\hline
\end{tabular}

PR, prevalence ratio of BMI; WC, waist circumference; WHR, waist:hip ratio; WSR, waist:stature ratio.

Significantly different compared with PR of a model with BMI (independent $t$ test): ${ }^{*} P<0.05$.

tHypertension was defined as systolic blood pressure $\geq 140 \mathrm{mmHg}$, diastolic blood pressure $\geq 90 \mathrm{mmHg}$ or being diagnosed by a doctor.

$\ddagger$ The samples included participants who were 18- to 65-year-old men and women (not pregnant or lactating), for whom measurements of anthropometric indices and blood pressure were complete and plausible (e.g. BMI of $15-35 \mathrm{~kg} / \mathrm{m}^{2}$, weight of $30-150 \mathrm{~kg}$, height of $130-190 \mathrm{~cm}$, WC of $45-150 \mathrm{~cm}$, hip circumference of $55-155 \mathrm{~cm}$, WHR of $0 \cdot 6-1 \cdot 1$, difference between systolic and diastolic blood pressure $\geq 10 \mathrm{mmHg}$ ).

$\S \%$ change $=100 \times$ absolute[ $\left[\mathrm{In}\left(\mathrm{PR}_{\mathrm{BMI}} / \mathrm{PR}_{\text {Test variables }}\right)\right]$; test variables were $\mathrm{BMI}+\mathrm{WC}, \mathrm{BMI}+\mathrm{WSR}$ or $\mathrm{BMI}+\mathrm{WHR}$.

$\| P$ value of the increase in model fit compared with a model with BMI (likelihood ratio test).

- Crude models: include independent variables in the list; crude PR for each unit increase in BMI.

t+Age-adjusted models: independent variables + age; age-adjusted PR for each unit increase in BMI.

¥Age-specific model: independent variables + age + (age $\times \mathrm{BMI})$; PR for each unit increase in BMI at the age of 45 years.

Table 3 Sex-specific AUC for the prediction of hypertension by different anthropometric indicest,‡

\begin{tabular}{|c|c|c|c|c|c|c|c|c|c|c|}
\hline \multirow[b]{2}{*}{ Model } & \multirow[b]{2}{*}{ Independent variable } & \multicolumn{3}{|c|}{ Women (n 3794) } & \multicolumn{3}{|c|}{ Men ( $n$ 3542) } & \multicolumn{3}{|c|}{ Both sexes $(n 7336)$} \\
\hline & & AUC\$ & $95 \% \mathrm{Cl}$ & $\%$ changell & AUC & $95 \% \mathrm{Cl}$ & $\%$ change & AUC & $95 \% \mathrm{Cl}$ & $\%$ change \\
\hline \multirow[t]{7}{*}{ Crude model } & $\mathrm{BMI}$ & $0 \cdot 71$ & $0 \cdot 68,0 \cdot 73$ & & 0.67 & $0.65,0.69$ & & 0.69 & $0 \cdot 67,0 \cdot 70$ & \\
\hline & WC & $0 \cdot 72$ & $0.69,0.74$ & $1 \cdot 1$ & 0.67 & $0.65,0.70$ & 0.5 & $0 \cdot 70$ & $0.68,0.71$ & 1.9 \\
\hline & WSR & 0.72 & $0 \cdot 70,0 \cdot 74$ & $2 \cdot 2$ & $0 \cdot 68$ & $0.66,0.70$ & $1 \cdot 7$ & 0.69 & $0 \cdot 68,0 \cdot 71$ & $1 \cdot 1$ \\
\hline & WHR & $0 \cdot 64^{\star}$ & $0.61,0.66$ & $10 \cdot 4$ & $0 \cdot 64$ & $0.62,0.67$ & $4 \cdot 1$ & $0 \cdot 65^{*}$ & $0.63,0.66$ & $5 \cdot 9$ \\
\hline & $\mathrm{BMI}+\mathrm{WC}$ & $0 \cdot 73^{\star \star \star}$ & $0 \cdot 70,0 \cdot 75$ & $2 \cdot 5$ & $0 \cdot 68^{\star \star \star}$ & $0 \cdot 66,0 \cdot 70$ & $1 \cdot 9$ & $0 \cdot 71^{\star \star \star}$ & $0.69,0.72$ & $3 \cdot 0$ \\
\hline & BMI + WSR & $0 \cdot 73^{\star \star \star}$ & $0 \cdot 71,0 \cdot 75$ & $3 \cdot 4$ & $0 \cdot 69^{\star \star \star}$ & $0.67,0.71$ & $2 \cdot 5$ & $0 \cdot 70^{\star \star \star}$ & $0.69,0.72$ & $2 \cdot 5$ \\
\hline & $\mathrm{BMI}+\mathrm{WHR}$ & $0 \cdot 72^{\star \star \star}$ & $0.69,0.74$ & $1 \cdot 3$ & $0 \cdot 68^{\star \star \star}$ & $0.66,0.71$ & $2 \cdot 0$ & $0 \cdot 70^{\star \star \star}$ & $0.69,0.72$ & $2 \cdot 2$ \\
\hline \multirow[t]{7}{*}{ Age-adjustedt† } & $\mathrm{BMI}$ & $0 \cdot 79$ & $0 \cdot 77,0 \cdot 81$ & & $0 \cdot 74$ & $0 \cdot 72,0 \cdot 76$ & & $0 \cdot 76$ & $0 \cdot 75,0 \cdot 78$ & \\
\hline & WC & $0 \cdot 78$ & $0.76,0.80$ & $1 \cdot 0$ & $0 \cdot 74$ & $0.72,0.76$ & $0 \cdot 8$ & $0 \cdot 76$ & $0.75,0.77$ & $0 \cdot 1$ \\
\hline & WSR & $0 \cdot 78$ & $0 \cdot 76,0 \cdot 80$ & $1 \cdot 5$ & 0.73 & $0.72,0.75$ & $1 \cdot 1$ & $0 \cdot 75$ & $0 \cdot 74,0 \cdot 76$ & $1 \cdot 8$ \\
\hline & WHR & 0.75 & $0.73,0.77$ & $4 \cdot 8$ & 0.72 & $0 \cdot 70,0 \cdot 74$ & $3 \cdot 8$ & $0 \cdot 73^{\star}$ & $0 \cdot 72,0 \cdot 75$ & $3 \cdot 8$ \\
\hline & $\mathrm{BMI}+\mathrm{WC}$ & $0 \cdot 79^{\star \star \star}$ & $0 \cdot 78,0 \cdot 81$ & $0 \cdot 3$ & $0 \cdot 75^{\star \star \star}$ & $0.73,0.77$ & $0 \cdot 7$ & $0 \cdot 77^{\star \star \star}$ & $0 \cdot 76,0 \cdot 78$ & 0.9 \\
\hline & BMI + WSR & $0 \cdot 79^{\star \star}$ & $0 \cdot 77,0 \cdot 81$ & $0 \cdot 2$ & $0 \cdot 75^{\star \star \star}$ & $0.73,0.77$ & 0.5 & $0 \cdot 76^{\star \star \star}$ & $0 \cdot 75,0 \cdot 78$ & $0 \cdot 2$ \\
\hline & $\mathrm{BMI}+\mathrm{WHR}$ & $0 \cdot 79^{N S}$ & $0 \cdot 77,0.81$ & $0 \cdot 1$ & $0 \cdot 75^{\star \star \star}$ & $0.73,0.77$ & $0 \cdot 6$ & $0 \cdot 77^{\star \star \star}$ & $0 \cdot 75,0 \cdot 78$ & 0.6 \\
\hline \multirow[t]{4}{*}{ Age-specificł‡ } & $\mathrm{BMI}$ & 0.79 & $0 \cdot 77,0 \cdot 81$ & & $0 \cdot 74$ & $0 \cdot 72,0 \cdot 76$ & & $0 \cdot 76$ & $0 \cdot 75,0 \cdot 78$ & \\
\hline & BMI + WC & $0 \cdot 79^{\star \star \star}$ & $0 \cdot 78,0 \cdot 81$ & $0 \cdot 3$ & $0 \cdot 75^{\star \star \star}$ & $0.73,0.77$ & $0 \cdot 7$ & $0 \cdot 77^{\star \star \star}$ & $0 \cdot 76,0 \cdot 78$ & 0.9 \\
\hline & BMI + WSR & $0 \cdot 79^{\star \star}$ & $0 \cdot 77,0 \cdot 81$ & $0 \cdot 2$ & $0 \cdot 75^{\star \star \star}$ & $0.73,0.77$ & 0.5 & $0 \cdot 76^{\star \star \star}$ & $0.75,0.78$ & 0.2 \\
\hline & $\mathrm{BMI}+\mathrm{WHR}$ & $0.79^{N S}$ & $0 \cdot 77,0 \cdot 81$ & $0 \cdot 1$ & $0 \cdot 75^{\star \star \star}$ & $0.73,0.77$ & $0 \cdot 6$ & $0 \cdot 77^{\star \star \star}$ & $0.75,0.78$ & 0.6 \\
\hline
\end{tabular}

AUC, area under the receiver-operating characteristic curve; WC, waist circumference; WSR, waist:stature ratio; WHR, waist:hip ratio.

Significantly different compared with a model with BMI (independent $t$ test): ${ }^{*} P<0.05$.

Significant increase in model fit compared with a model with BMI (likelihood ratio test): ${ }^{\star *} P<0.005,{ }^{\star * *} P<0.001, \mathrm{NS}, P=0.07$.

tHypertension was defined as systolic blood pressure $\geq 140 \mathrm{mmHg}$, diastolic blood pressure $\geq 90 \mathrm{mmHg}$ or being diagnosed by a doctor.

¥The samples included participants who were 18- to 65-year-old men and women (not pregnant or lactating), for whom measurements of anthropometric indices and blood pressure were complete and plausible (e.g. BMl of $15-35 \mathrm{~kg} / \mathrm{m}^{2}$, weight of $30-150 \mathrm{~kg}$, height of $130-190 \mathrm{~cm}$, WC of $45-150 \mathrm{~cm}$, hip circumference of 55-155 cm, WHR of $0 \cdot 6-1 \cdot 1$, difference between systolic and diastolic blood pressure $\geq 10 \mathrm{mmHg}$ ).

§AUC values range from 0.5 (no prediction) to 1.0 (perfect prediction); estimated by using logistic regression models.

$\| \%$ change $=100 \times$ absolute[In(AUC $\left.\left.{ }_{B M I} / A_{U} C_{\text {Test variables }}\right)\right]$; test variables were WC, WSR, WHR, BMI + WC, BMI + WSR or BMI + WHR.

Crude models: include independent variables in the list.

t+Age-adjusted models: independent variables + age.

$\ddagger \ddagger$ Age-specific model: independent variables + age $+($ age $\times \mathrm{BMI})$.

in a study by Lin $e t a l{ }^{(10)}$. Their protocols for the measurements of weight, height, WC, HC and blood pressures were similar to ours. Based on their data, we computed the difference in AUC based on the sex-specific AUC of each risk factor or disease condition (e.g. hypertension, diabetes mellitus, dislipidaemia, elevated TAG, total cholesterol or LDL cholesterol, or decreased HDL cholesterol). WC, WSR or WSR was not superior $(<10 \%$ 
increase in AUC) to BMI in the prediction of any risk factors or disease conditions in women or men.

We also computed the difference in AUC with the use of sex-specific AUC from a sample of 2895 Hong Kong Chinese in a study by Ho et al. $^{(7)}$. WC provided similar predictions to BMI in the examined diseases and metabolic risk factors (except for stroke in women), while WHR and WSR were better than BMI in some predictions (e.g. hypertension and CVD (men); dislipidaemia (women); and fasting glucose, diabetes and stroke (men and women)). There are three potential explanations for the differences. First, the study by Ho et al. ${ }^{(7)}$ was based on a non-representative sample: participants were recruited by telephone (response rate of $78 \%$ ), and only $38 \%$ of responders were examined and included in the final sample. Those participants might have very different disease patterns, risk factors and health-related behaviours compared with the non-participants ${ }^{(33)}$. Second, Ho et al.'s study ${ }^{(7)}$ included 65- to 74-year-old participants who might have: (i) a lower WC measured at a high location (Ho et al. measured WC at midway between the xiphisternum and the umbilicus), which would underestimate abdominal fat and overestimate the prediction of WC; and (ii) a higher BMI due to a biological decrease in height which would underestimate the prediction of BMI. As a result, there would be an increase in the prediction of WC, WSR or WHR compared with BMI. Third, WC measured in the Ho et al.'s study ${ }^{(7)}$ was systematically smaller than ours (we measured WC midway between the lowest rib and the iliac crest) ${ }^{(34)}$. Decreased WSR and WHR, resulting from the smaller WC, would bias the association between WSR and WHR away from the null and would increase their predictions compared with that of BMI.

Our study showed a tendency toward increased prediction of hypertension by WC, WSR or WHR among participants with a lower BMI (e.g. BMI $<23 \mathrm{~kg} / \mathrm{m}^{2}$ ). The finding is consistent with those of Ardern et l. $^{(35)}$, in which the association between WC and cardiovascular risk was stronger at a lower BMI. However, the studies are not directly comparable. Their sample included American (white, black and Hispanic) and Canadian participants who differed from our Chinese participants in age, body composition, lifestyles and socio-economic characteristics. Also, Ardern et al. ${ }^{(35)}$ used the Framingham CHD risk index as study outcome, while we used hypertension.

We would have concluded that WC, WSR or WHR added to the prediction of hypertension by BMI (this finding being consistent with other studies ${ }^{(5,9,12)}$ ) if a $P$ value of $<0.05$ in a likelihood ratio test had been used as a decision criterion. However, this criterion is not the best choice because a $P$ value varies with both the magnitude of effect and the sample size ${ }^{(13,14)}$. For example, with a large sample size, we could detect a small difference (e.g. $P$ value $<0 \cdot 05)$; in contrast, with a small sample size, we may not detect a large difference (e.g. $P$ value $>0 \cdot 05$ ). Our methods are expected to be more stable to the variation in sample size because the estimations of PR, AUC and the change in those estimates are less likely to be affected by the changes sample size ${ }^{(15,16)}$. In addition, our sensitivity analyses, in which samples of $50 \%$ and $10 \%$ of the original sample were selected randomly, showed that $P$ value is more sensitive to changes in sample size than is percentage change in PR and AUC.

In the context of a developing country, it is important to find a small number of practical, low-cost and culturally accepted anthropometric indices to predict elevated disease burdens ${ }^{(36,37)}$. In a population or clinical setting among Chinese adults, BMI appears to be sufficient because: (i) the exclusion of WC will save time, money and human resources; and (ii) the interpretation of a WC value would be confusing because of the lack of a universally accepted site for measuring $\mathrm{WC}$ and the large variation of WC optimal cut-offs by sex, age, races, ethnicities, BMI levels and health outcomes of interest ${ }^{(2)}$. Even in the USA, most of the treatment recommendations (99.9\% for men and $98.5 \%$ for women; data from the Third National Health and Nutrition Examination Survey) were based on the evaluation of BMI and cardiovascular risk factors, regardless of the measured $\mathrm{WC}^{(38)}$.

In conclusion, the present study showed that even though WC, WSR and WHR are predictors of hypertension, they do not perform better than BMI or add to the prediction of hypertension by BMI in Chinese adults. The comparison of $\mathrm{PR}$ and AUC, instead of $P$ value or $95 \% \mathrm{CI}$, is considered a strength and a methodological contribution of the present study. Further studies with other outcomes (e.g. glucose intolerance, diabetes mellitus, dyslipidaemia, mortality or events of CVD/non-communicable diseases) and more detailed information about body composition (e.g. total abdominal adipose tissue, visceral adipose tissue, total body fat mass) in representative samples of Chinese, other Asian and Western populations are still needed to confirm the consistency of the finding. Nevertheless, our conclusions about the value of using BMI to predict hypertension are meaningful for decision making in public health and clinical settings. Compared with WC, height and weight and thus BMI are: (i) collected more often in nutrition and health surveys, interventions and in clinics; (ii) collected with the use of universally accepted protocols; and (iii) easier to interpret.

\section{Acknowledgements}

Sources of funding: The research was financially supported in part by the Vietnam Educational Foundation (VEF), the National Institutes of Health (NIH; R01HD30880, HD38700, DK056350 and DK533951) and the Fogarty International Center, NIH for financial support for the CHNS data collection and analysis files. Conflict of interest declaration: None of the authors had a conflict of interest related to any part of this study or manuscript. 
Author contributions: N.T.T. designed the study, acquired the data, analysed and interpreted the data, and drafted the manuscript. L.S.A. assisted in the analysis and interpretation of the data, and provided critical intellectual feedback for the manuscript. J.S. assisted in the interpretation of the data and provided critical intellectual feedback for the manuscript. B.M.P. assisted in the study design and interpretation of the data, and provided critical intellectual feedback for the manuscript. All authors have read and approved the final version of the manuscript. Acknowledgements: We thank Dr Chirayath Suchindran and Dr Ka He for critically reading the article, Bill Shapbell for editing and Frances Dancy for administrative assistance.

\section{References}

1. Gibson R (2005) Principles of Nutritional Assessment, 2nd ed. New York: Oxford University Press.

2. Klein S, Allison DB, Heymsfield SB, Kelley DE, Leibel RL, Nonas C \& Kahn R (2007) Waist circumference and cardiometabolic risk: a consensus statement from Shaping America's Health: Association for Weight Management and Obesity Prevention; NAASO, The Obesity Society; the American Society for Nutrition; and the American Diabetes Association. Am J Clin Nutr 85, 1197-1202.

3. Visscher TL, Seidell JC, Molarius A, van der Kuip D, Hofman A \& Witteman JC (2001) A comparison of body mass index, waist-hip ratio and waist circumference as predictors of all-cause mortality among the elderly: the Rotterdam study. Int $J$ Obes Relat Metab Disord 25 , $1730-1735$.

4. Benetou V, Bamia C, Trichopoulos D, Mountokalakis T, Psaltopoulou T \& Trichopoulou A (2004) The association of body mass index and waist circumference with blood pressure depends on age and gender: a study of 10,928 non-smoking adults in the Greek EPIC cohort. Eur $J$ Epidemiol 19, 803-809.

5. Zhu S, Wang Z, Heshka S, Heo M, Faith MS \& Heymsfield SB (2002) Waist circumference and obesity-associated risk factors among whites in the third National Health and Nutrition Examination Survey: clinical action thresholds. Am J Clin Nutr 76, 743-749.

6. Ho SC, Chen YM, Woo JL, Leung SS, Lam TH \& Janus ED (2001) Association between simple anthropometric indices and cardiovascular risk factors. Int J Obes Relat Metab Disord 25, 1689-1697.

7. Ho SY, Lam TH \& Janus ED (2003) Waist to stature ratio is more strongly associated with cardiovascular risk factors than other simple anthropometric indices. Ann Epidemiol 13, 683-691.

8. Hsieh SD, Yoshinaga H \& Muto T (2003) Waist-to-height ratio, a simple and practical index for assessing central fat distribution and metabolic risk in Japanese men and women. Int J Obes Relat Metab Disord 27, 610-616.

9. Ito H, Nakasuga K, Ohshima A, Maruyama T, Kaji Y, Harada M, Fukunaga M, Jingu S \& Sakamoto M (2003) Detection of cardiovascular risk factors by indices of obesity obtained from anthropometry and dual-energy X-ray absorptiometry in Japanese individuals. Int J Obes Relat Metab Disord 27, 232-237.

10. Lin WY, Lee LT, Chen CY, Lo H, Hsia HH, Liu IL, Lin RS, Shau WY \& Huang KC (2002) Optimal cut-off values for obesity: using simple anthropometric indices to predict cardiovascular risk factors in Taiwan. Int J Obes Relat Metab Disord 26, 1232-1238.
11. Sakurai M, Miura K, Takamura $\mathrm{T}$, Ota $\mathrm{T}$, Ishizaki $\mathrm{M}$, Morikawa Y, Kido T, Naruse Y \& Nakagawa H (2006) Gender differences in the association between anthropometric indices of obesity and blood pressure in Japanese. Hypertens Res 29, 75-80.

12. Wildman RP, Gu D, Reynolds K, Duan X, Wu X \& He J (2005) Are waist circumference and body mass index independently associated with cardiovascular disease risk in Chinese adults? Am J Clin Nutr 82, 1195-1202.

13. Weinberg CR (2001) It's time to rehabilitate the $P$-value. Epidemiology 12, 288-290.

14. Rothman K, Greenland S \& Lash T (2008) Precision and statistics in epidemiologic studies. In Modern Epidemiology, 3rd ed., pp. 148-167 [S Greenland, K Rothman and T Lash, editors]. Philadelphia, PA: Lippincott Williams \& Wilkins.

15. Greenland S \& Rothman K (2008) Introduction to stratified analysis. In Modern Epidemiology, 3rd ed., pp. 258-282 [S Greenland, K Rothman and T Lash, editors]. Philadelphia, PA: Lippincott Williams \& Wilkins.

16. Zweig MH \& Campbell G (1993) Receiver-operating characteristic (ROC) plots: a fundamental evaluation tool in clinical medicine. Clin Chem 39, 561-577.

17. Carolina Population Center, University of North Carolina (2007) China Health and Nutrition Survey. Chapel Hill, NC: CPC, UNC-CH; also available at http://www.cpc.unc. edu/china

18. Popkin BM, Paeratakul S, Zhai F \& Ge K (1995) Dietary and environmental correlates of obesity in a population study in China. Obes Res 3, Suppl. 2, 135s-143s.

19. World Health Organization (1995) Physical Status: The Use and Interpretation of Anthropometry. Report of a WHO Expert Committee. Geneva: WHO.

20. Chobanian AV, Bakris GL, Black HR et al. (2003) The Seventh Report of the Joint National Committee on Prevention, Detection, Evaluation, and Treatment of High Blood Pressure: the JNC 7 report. JAMA 289, 2560-2572.

21. Balkau B, Deanfield JE, Despres JP et al. (2007) International Day for the Evaluation of Abdominal Obesity (IDEA): a study of waist circumference, cardiovascular disease, and diabetes mellitus in 168,000 primary care patients in 63 countries. Circulation 116, 1942-1951.

22. Colin Bell A, Adair LS \& Popkin BM (2002) Ethnic differences in the association between body mass index and hypertension. Am J Epidemiol 155, 346-353.

23. Tesfaye F, Nawi NG, Van Minh H, Byass P, Berhane Y, Bonita R \& Wall S (2007) Association between body mass index and blood pressure across three populations in Africa and Asia. J Hum Hypertens 21, 28-37.

24. Weng X, Liu Y, Ma J, Wang W, Yang G \& Caballero B (2006) Use of body mass index to identify obesity-related metabolic disorders in the Chinese population. Eur J Clin Nutr 60, 931-937.

25. Wildman RP, Gu D, Reynolds K, Duan X \& He J (2004) Appropriate body mass index and waist circumference cutoffs for categorization of overweight and central adiposity among Chinese adults. Am J Clin Nutr 80, $1129-1136$.

26. Canoy D, Luben R, Welch A, Bingham S, Wareham N, Day N \& Khaw KT (2004) Fat distribution, body mass index and blood pressure in 22,090 men and women in the Norfolk cohort of the European Prospective Investigation into Cancer and Nutrition (EPIC-Norfolk) study. J Hypertens 22, 2067-2074.

27. Dalton M, Cameron AJ, Zimmet PZ, Shaw JE, Jolley D, Dunstan DW \& Welborn TA (2003) Waist circumference, waist-hip ratio and body mass index and their correlation with cardiovascular disease risk factors in Australian adults. J Intern Med 254, 555-563. 
28. Kaplan N (2006) Primary hypertension: pathogenesis. In Kaplan's Clinical Hypertension, 9th ed., pp. 50-121 [N Kaplan, editor]. Philadelphia, PA: Lippincott Williams \& Wilkins.

29. Pavey B, Plalmer J, Sowers J \& Stump C (2006) Hypertension and diabetes mellitus. In Molecular Mechanisms in Hypertension, pp. 361-374 [R Re, D DiPette, E Schiffrin and J Sowers, editors]. London: Taylor \& Francis.

30. Deurenberg P, Deurenberg-Yap M \& Guricci S (2002) Asians are different from Caucasians and from each other in their body mass index/body fat per cent relationship. Obes Rev 3, 141-146.

31. Lear SA, Humphries KH, Kohli S, Chockalingam A, Frohlich JJ \& Birmingham CL (2007) Visceral adipose tissue accumulation differs according to ethnic background: results of the Multicultural Community Health Assessment Trial (M-CHAT). Am J Clin Nutr 86, 353-359.

32. Park YW, Allison DB, Heymsfield SB \& Gallagher D (2001) Larger amounts of visceral adipose tissue in Asian Americans. Obes Res 9, 381-387.
33. Grimes DA \& Schulz KF (2002) Bias and causal associations in observational research. Lancet 359, 248-252.

34. Wang J, Thornton JC, Bari S et al. (2003) Comparisons of waist circumferences measured at 4 sites. Am J Clin Nutr 77, 379-384.

35. Ardern CI, Janssen I, Ross R \& Katzmarzyk PT (2004) Development of health-related waist circumference thresholds within BMI categories. Obes Res 12, 1094-1103.

36. Popkin BM, Kim S, Rusev ER, Du S \& Zizza C (2006) Measuring the full economic costs of diet, physical activity and obesity-related chronic diseases. Obes Rev 7, 271-293.

37. World Health Organization (2003) The World Health Report 2002. Geneva: WHO.

38. Kiernan M \& Winkleby MA (2000) Identifying patients for weight-loss treatment: an empirical evaluation of the NHLBI obesity education initiative expert panel treatment recommendations. Arch Intern Med 160, 2169-2176. 